\title{
The Chemistry of Olive Oil: an endless story ${ }^{\star}$
}

\author{
Lanfranco Conte ${ }^{1,2, *, a}$ \\ ${ }^{1}$ Department of Agriculture, Food Environmental, Animal Sciences, University of Udine, 33100 Udine, Italia \\ 2 Società Italiana per lo Studio delle Sostanze Grasse, Milano, Italia
}

Received 17 February 2020 - Accepted 23 March 2020

\begin{abstract}
Because of their value, Olive oils, undergo to several attempts of adulteration and this improved the performances of analytical methods developed to check their authenticity. After the eve of the "Chemistry of indexes", the development of separation techniques greatly improved the knowledge of the composition of lipids; the earlier gas chromatographic separations of fatty acid, could last even more than 40 minutes and the evaluation of minor fatty acids were problematic, at Bologna University, their previous separation on silver nitrate silica gel TLC was applied in 1974-1975, in order to concentrate them and obtain a better chromatogram. The gas chromatographic evaluation of minor compounds was another interesting challenge, packed columns with apolar stationary phase, admit the separation of few peaks; in 1975, the use of a slightly more polar stationary phase (OV17) highlighted the presence of $\Delta-5$-avenasterol in olive oils. 1981 is a milestone for olive oil analytical control: Regulation (CEE) 2568/91 made the use of capillary columns mandatory. Official analytical methods consider many parameters, enclosed sensory evaluation, that is not matter for chemists, however, chemists are moved by curiosity and several papers had been published on the relationship between the volatile compounds of head space of olive oil and sensory characteristics. Despite being one of the more studied food, olive oils' composition continues to give the chemists the possibility to discover new compounds, e.g. degradation products of sterols that leads to the standardization of the method for sterenes evaluation. From 1973 to nowadays, the laboratory performances greatly improved, nowadays it is possible to generate a huge number of data in a short time, then the problem is how to correctly interpretate them, surely chemometric and lipidomic greatly can help.
\end{abstract}

Keywords: olive oils / authenticity / fatty acids / minor compounds / chromatography

Résumé - La chimie de l'huile d'olive : une histoire sans fin. En raison de leur valeur, les huiles d'olive subissent de nombreuses tentatives d'adultération, ce qui pousse à améliorer les performances des méthodes d'analyse développées pour vérifier leur authenticité. Après l'émergence de la "Chimie des indices», le développement des techniques de séparation a grandement amélioré la connaissance de la composition des lipides. Les premières séparations par chromatographie en phase gazeuse des acides gras pouvaient durer plus de 40 minutes et l'évaluation des acides gras mineurs était problématique. À l'université de Bologne, la séparation de ces acides gras par chromatographie en couche mince sur gel de silice contenant du nitrate d'argent a été appliquée en 1974-1975. Ceci a permis de les concentrer et d'obtenir un meilleur chromatogramme. L'évaluation des composés mineurs par chromatographie en phase gazeuse était un autre défi intéressant, les colonnes remplies avec une phase stationnaire apolaire permettaient la séparation de quelques pics. En 1975, l'utilisation d'une phase stationnaire légèrement plus polaire (OV17) a permis de mettre en évidence la présence de $\Delta$-5-avenastérol dans les huiles d'olive. 1981 est une étape importante pour le contrôle analytique des huiles d'olive : le règlement (CEE) 2568/91 rendit obligatoire l'utilisation de colonnes capillaires. Les méthodes d'analyse officielles prennent en compte de nombreux paramètres, incluant l'évaluation sensorielle, ce qui n'est pas l'affaire des chimistes. Cependant, les chimistes sont

\footnotetext{
^ The 2019 Chevreul Medal lecture, 17th Euro Fed Lipid Congress (20-23 October 2019, Seville, Spain)

*Correspondence: lanfrancoconte@gmail.com

${ }^{a}$ Retired, Formerly full Professor of Food Chemistry at the Department of Agriculture, Food, Environmental and Animal Sciences University of Udine, 33100 Udine, Italia
} 
poussés par la curiosité et plusieurs articles ont été publiés sur la relation entre les composés volatils de 1 trouvés dans l'espace de tête et les caractéristiques sensorielles de l'huile d'olive. Bien qu'elle soit l'un des aliments les plus étudiés, la composition des huiles d'olive continue de donner aux chimistes la possibilité de découvrir de nouveaux composés, par exemple les produits de dégradation des stérols, ce qui conduisit à la standardisation de la méthode d'évaluation des stérènes... De 1973 à nos jours, les performances des laboratoires se sont grandement améliorées. Il est aujourd'hui possible de générer un grand nombre de données en peu de temps; le problème est davantage de savoir les interpréter correctement. À ce titre, il semble très probable que la chimiométrie et la lipidomique seront d'une grande aide.

Mots clés : huile d'olive / contrôle de la qualité / contrôle de la pureté / évolution des méthodes analytiques

\section{Introduction}

The assessment of purity of foods had been an hot topic through the whole human history, the higher was the value of a food, the higher were the possibilities that is underwent to tentative of frauds; Romans greatly appreciated the olive oil produced in the Liburnia Region (nowadays the area of Rjieka, Croatia), but the delivery from that region to Rome was dangerous, so that they imported oils from Hispania Baetica, but a recipe was found describing how to add some flavors to this oil to sell it as a Liburnia's one.

Closely near to nowadays, in 1848 a treatise on falsification of foods was published in London, saying, among other topic that olive oils was more prone than other to adulteration.

Olive oils, as well as any other food must full fit two categories of parameters: purity and quality parameters; the main difference is that purity parameters are "trenchant", do not admit any waive (Fig. 1).

Quality parameters, instead are a ranking tool, even if, of course, once a quality had been declared, it is mandatory to respect it. (Fig. 2).

In the beginning, to check for olive oil purity and quality, analysts were compelled to use some tests of the so-called "Chemistry of indexes" because they were within the Italian legislation.

Some examples are reported in Table 1; in some cases, they were chromatic (not colorimetric) reactions e.g. the Kreiss reaction for rancidity, the Halphen reaction to assess the presence of Malvaceae oils (that are characterized by the presence of fatty acids with cyclopropane and cyclopropene ring), or the reaction of Villavecchia Fabris and later Isodoro Pavolini, used to look for the presence of sesame oil that in Italy at that eve was mandatory added to seed oils. A number of false positive results occurred.

In the meantime, the use of gas chromatography to evaluate the composition of fatty acids was adopted by the legislation and began to be extensively used.

Packed columns were used, main polar stationary phases being esters of succinic and adipic acids (e.g. DEGS or LAC), supported on different inert support as Chromosorb or similar.

Columns were usually stainless steel tubes $2 \mathrm{~mm}$ internal diameter, $2 \mathrm{~m}$ long.

When a programmed temperature was used, the baseline drift was corrected by using two identic columns connected to different electric polarity detectors (FID).

The long time of analysis involved a poor shape of long RT peaks that furthermore was also those with a lower concentration; to obtain a more performing GC trace, a preliminary separation by means of Silver $\mathrm{AgNO}_{3}$ was proposed and the fraction of saturated fatty acids was then analyzed by means of a non polar packed column (JXR, $3 \mathrm{mt}$ length) (Fig. 3) (Capella et al., 1975).

Of course, the analysis of the fatty acids solely cannot be exhaustive both because more and more skilled fraudsters were able to produce mixed oils with a composition closely near to the one of olive oils and because seed oils with a fatty acids composition quite similar to olive oils were obtained by genetic improvement (e.g. Safflower, Sunflower); the analysis of sterols became therefore important and legally mandatory.

Packed columns with non polar stationary phases (e.g. SE30, JXR), 3 m length were used, however, some awareness was necessary, e.g. the use of glass columns, to avoid sterol thermic degradation depending on the contact with the hot stainless steel wall as well as to inactivate the glass hydroxyl group by silylating the empty column before pack it.

By such a column, few peaks were separated, later, the use of a slightly more polar stationary phase, named OV17 permitted the separation of $\Delta$-5-avenasterol from $\beta$-sitosterol.

However, a number of "minor" sterols cannot be separated and in this case, too, the use of TLC with Silver Silica was used to fraction sterols on the basis of their unsaturation degree, after conversion to acetyl derivatives, (Fig. 4) (Conte et al., 1979).

Even if the official method, at least in Italy, used only packed columns, capillary chromatography (by glass open tubular SCOT columns and later WCOT columns) was widespread used even if limited by practical drawbacks, because they were very fragile and in general the use was cumbersome depending on the not availability of devoted instruments. A number of adaptations were developed, e.g. the "falling needle" luckily, devoted GC with split splitless and cold on column injection became available and greatly improved our analytical possibilities.

The use of capillary columns also made the analysis of the fatty acids composition more fast and performing, not only in the field of olive oils, e.g. we reexamined the "half seed analysis", after the request of some Colleagues involved in genetic improvement of oils bearing seed plants: by using few seeds and carrying out an extraction and transmethylation in the same tube, a FAMEs mix was obtained suitable to be directly injected in the GC, of course, such a saving of time would be not important if the analysis was very time consuming, for this reason, the use of a short column $(15 \mathrm{~m})$ was decided in order to reduce the time of GC analysis (Fig. 5) (Conte et al., 1989). 


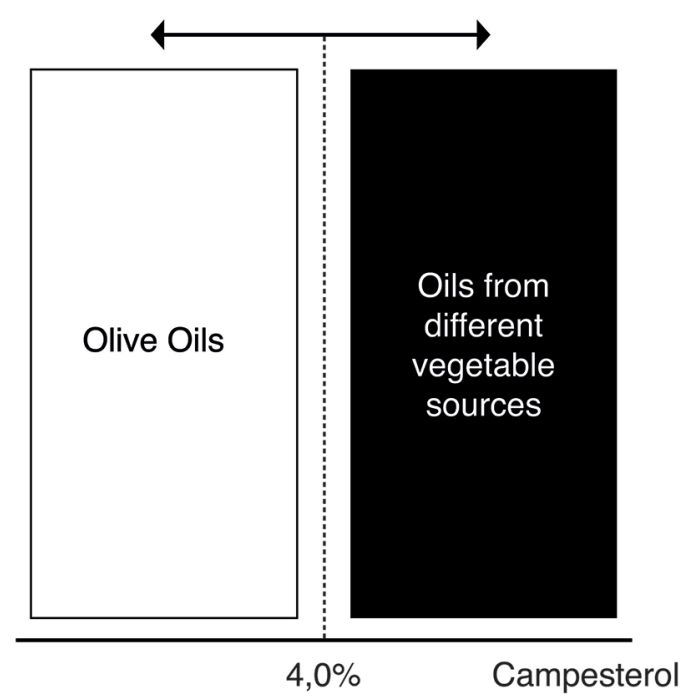

Fig. 1. Olive oil purity parameter: Strong discriminating effect.

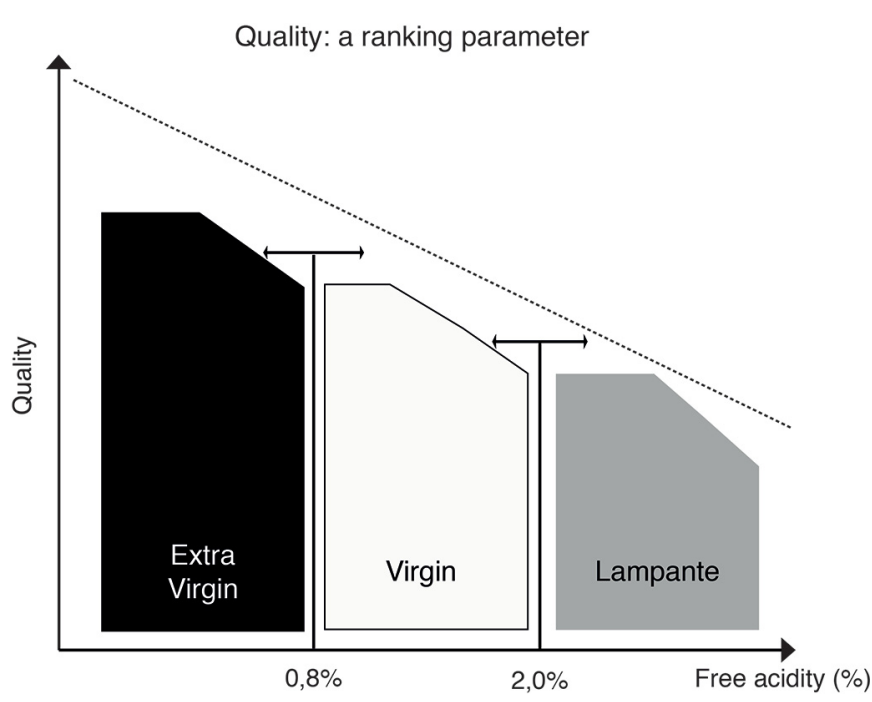

Fig. 2. Olive oil quality parameters: Use for ranking of different categories.

Table 1. The "chemistry of indexes" parameters and related meaning.

\begin{tabular}{ll}
\hline Index & Nowadays \\
\hline Refractive index & Unsaturation degree still used \\
Halphen reaction sterculic acid (Malvaceae oils) & No more used, GC of FAMEs and sterols \\
Villavecchia-Fabris and Isodoro Pavolini reactions (In Italy, for Sesame oil) & No more used, GC of FAMEs and sterols \\
Saponification Index & Amount of fatty acids, no more used \\
Esters index & Amount of TAGs, no more used \\
Iodine number & Unsaturation degree still used \\
Thermosulphuric index & Unsaturation degree no more used \\
Acidity index & Quality, still used \\
Peroxide value & Quality, still used \\
\hline
\end{tabular}

Of course, if the separation of critical compounds was request, longer columns were used, this is the case of trans isomers of fatty acids, which earlier separation was obtained by very long column (100-150 m of stainless steel Apiezon L).

The determination of trans isomers is important because this isomerization takes place in refining, as well as double bonds conjugation.

The latter are highlighted by UV absorption, in Italy, Montefredine and Laporta (1959) developed this method that because of being very effective, became an official one soon.

Fraudsters were however able to skip this tool at the best of our knowledge by treating oils before carry out refining, with maleic anhydride obtaining an adduct with double bonds that in such a way did not undergo to conjugation, trans isomers were formed, anyway, and Morchio et al. (1989) demonstrated this, by analyzing these oils with low UV absorptions by means of a Carbowax $20 \mathrm{M}$ capillary column, later a more stable stationary phase which polarity does not depend on the interrupt chain of a polyester but by different polar group (cyano groups). The method was then validated by the Italian Technical Committee (Amelio et al., 1993).
As already said, the analysis of sterols, too, greatly improved its performances thanks to the use of capillary columns, however, for some years, the only improvement was a reduction of time of analysis, because of national official methods that still used packed columns, so that chemists were compelled to sum several peaks to mime the results of the packed column.

In 1991, the Reg (EEC) 2568 was adopted and it uses capillary columns, however, in the case of B-sitosterol, several peaks must be sum to check the full fitting of the legal limit $(\geq 93.0 \%)$. This depends on the lack of a reliable database on the real values of B-sitosterol solely and on the widespread concentration values of $\Delta$-5-avenasterol.

The concentration of the latter is greatly influenced by several issues, as ripening degree of fruits, olive cultivar, area of cultivation and, when applied, refining.

Capillary GC was applied to sterol composition of a number of different plants since by Itoh et al. (1973), our group in Bologna University also characterized the composition of a number of other unsaponifiable fraction as tritherpenic alcohols, methylsterols and tocopherols (Fig. 6). 


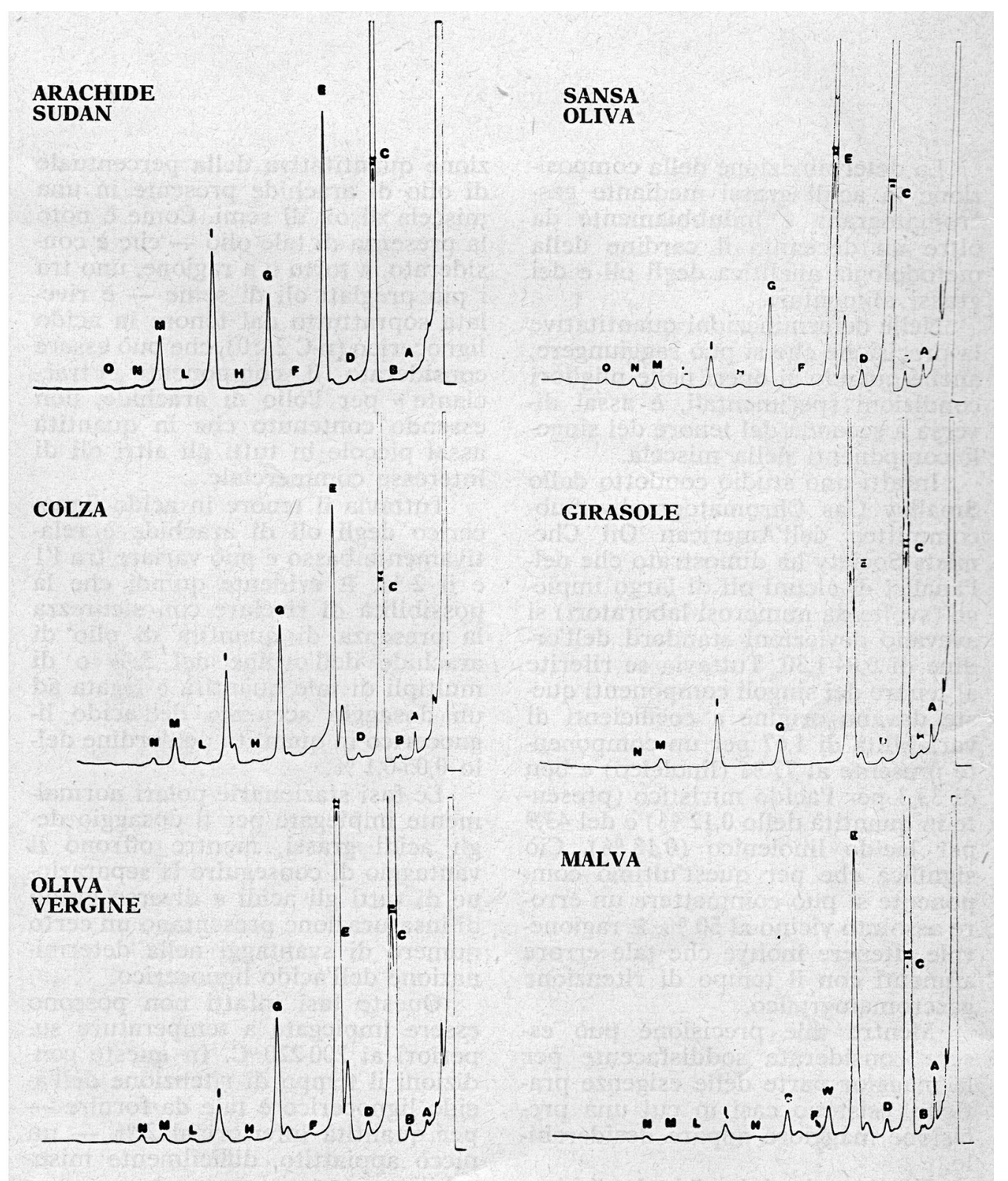

Fig. 3. Analysis of saturated fatty acids methyl esters, after $\mathrm{TLC} / \mathrm{AgNO}_{3}$ fractionation (Capella et al., 1975, reproduced under permission).

Sterols were recognized as the fingerprint of oils, not only on the basis of the presence of peculiar ones (e.g. brassicasterol in the case of rapeseed), but also because of their concentration.

Somebody "discovered" that applying very strong refining conditions, sterols can be "removed", for this reason, the "absolute" concentration of sterols was adopted as analytical parameter.

On the other hand, researchers of the Instituto de la Grasa in Sevilla (Cert et al., 1994) proposed to assess the presence of degradation products of sterols, to highlight this illegal procedure. This reaction had been studied by Niewiadomski (Niewiadomski, 1975) (Chevreul medial in 1967) that identified some hydrocarbons named sterenes.
The evaluation of stigmastadienes (the main product, deriving from B sitosterol) was adopted as ISO method, then by IOC and in 1995 by EU.

An early limit of $0.15 \mathrm{mg} / \mathrm{kg}$ for edible virgin olive oils was established, then it was revised to $0.10 \mathrm{mg} / \mathrm{kg}$ and few years ago to $0.05 \mathrm{mg} / \mathrm{kg}$. The adoption of a so low limit moved some criticism, mainly depending on the practical management of the bottling plants. It is well known that after bottling a refined oil, about $100 \mathrm{~kg}$ of the following virgin oil cannot be labeled as such, because of the high UV absorption values, this is true for stigmastadienes, too, which concentration results between 0.05 and 0.10 as an effect of cross contamination of pipes. 

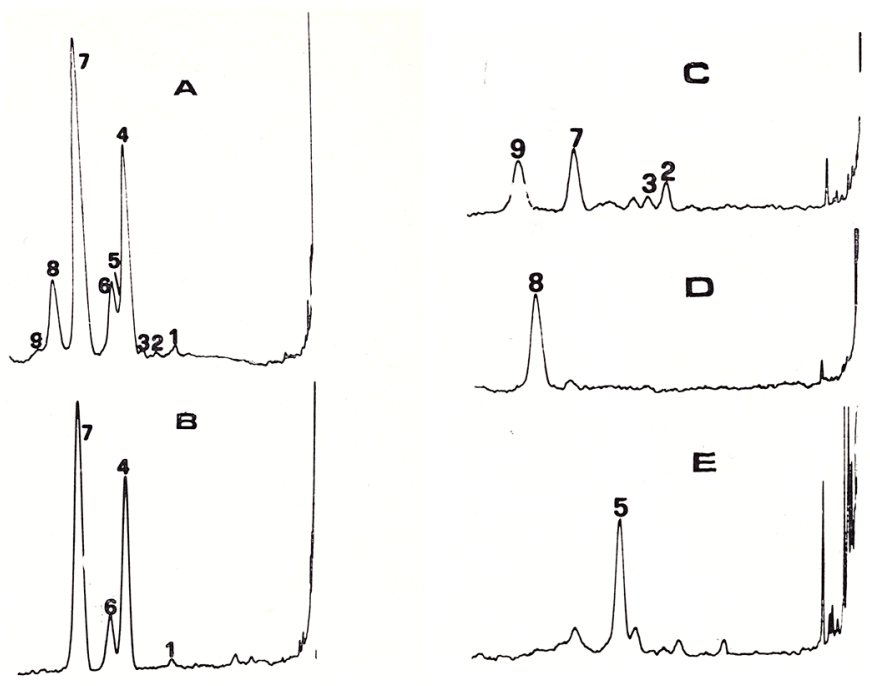

Fig. 4. Analysis of sterols (as acetyl derivatives), after $\mathrm{TLC} / \mathrm{AgNO}_{3}$ fractionation: A: Total sterols; $\mathrm{B}=\mathrm{TLC}$ band $\mathrm{Rf} 0.71 ; \mathrm{C}=\mathrm{TLC}$ band Rf $0.60 ; \mathrm{D}=\mathrm{TLC}$ band Rf $0.51 ; \mathrm{E}=\mathrm{TLC}$ band Rf 0.35. Peaks identification: 1: Cholesterol; 2: Brassicasterol; 3: Not identified; 4: Campesterol; 5: 24-methylencholesterol; 6: Stigmasterol; 7: ßsitosteol; 8: $\Delta$-5-avenasterol; 9: $\Delta$-7-stigmastenol (Conte et al., 1979 , reproduced under permission).

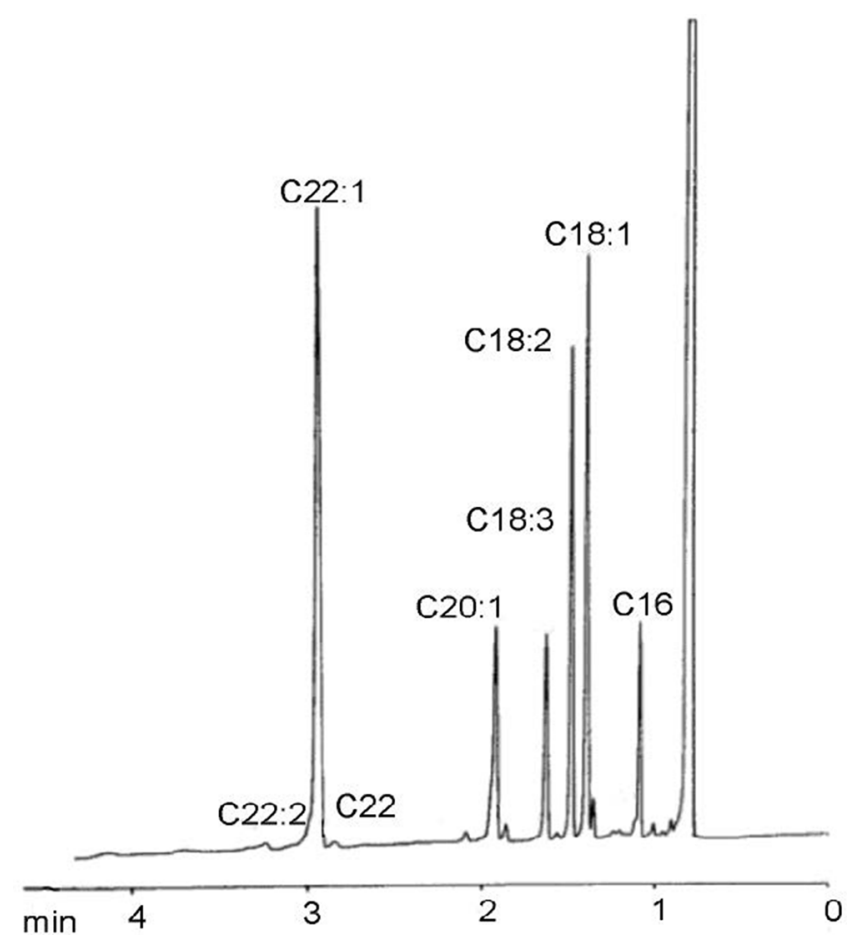

Fig. 5. Fast capillary GC analysis of FAMEs of rapeseed (Conte et al., 1989, reproduced under permission).

Bortolomeazzi et al. (2000) within the Udine Food Chemistry group studied what happens to sterol oxides that can be present in crude oils, in the case of Lampante oil, some sterol oxide are present that will undergo to degradation during refining.

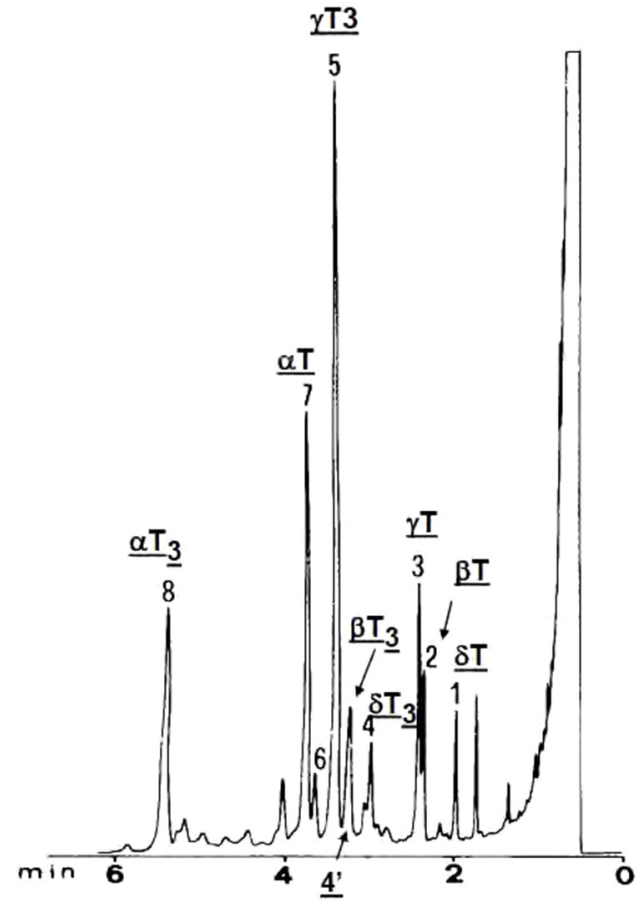

Fig. 6. Capillary gas chromatographic analysis of a blend of tocopherols and tocotrienols (palm oil and grapeseed oil) (Lercker et al., 1981, reproduced under permission).

Compounds of usaponifiable matter are usually known ad "minor" compounds, as fatty acids are of course "main compounds", however, the real "main compounds" are triacylglycerols, despite this, the analytical evaluation of these molecules was not carried out for a long time because of poor instrumental and stationary phases performances, mainly depending on the very high temperature necessary for their elution.

Separation of TAGs on packed columns were obtained on the basis of the carbon number and considered not very important and informative.

At the beginning of ' 80 , the group of Sandra (Geeraert and Sandra, 1985) introduced a polar, thermostable stationary phase that was then improved and was applied to get the separation of a number of TAGs isomers.

However, in the case of olive oils, no more application was developed.

I would like now to open a bracket as a side branch of the analysis of TAGs, since 1927, several studies (Hilditch, Kharta, Desnuelle) highlighted that in plants, the three position of the backbone of glycerol are preferentially esterified with different fatty acids, the usaturated being at $98 \%$ in the 2 position.

This scientific note was at the basis of the analytical method known as "pancreatic lipase" that after enzymatic hydrolysis produces 2-monoacylglycerols which fatty acid composition was evaluated, to check if the original TAG was obtained by biosynthesis of by chemical syntesys.

In Italy, this fraud was named by the "L'Espresso" newspaper as "The donkey in the bottle" because fats from by products of slaughter were used.

The method was rather cumbersome and time consuming, so that, after Motta (Motta et al., 1983) (who indeed worked on hydrogenated fats) published the analysis of MAGs and DAGs 

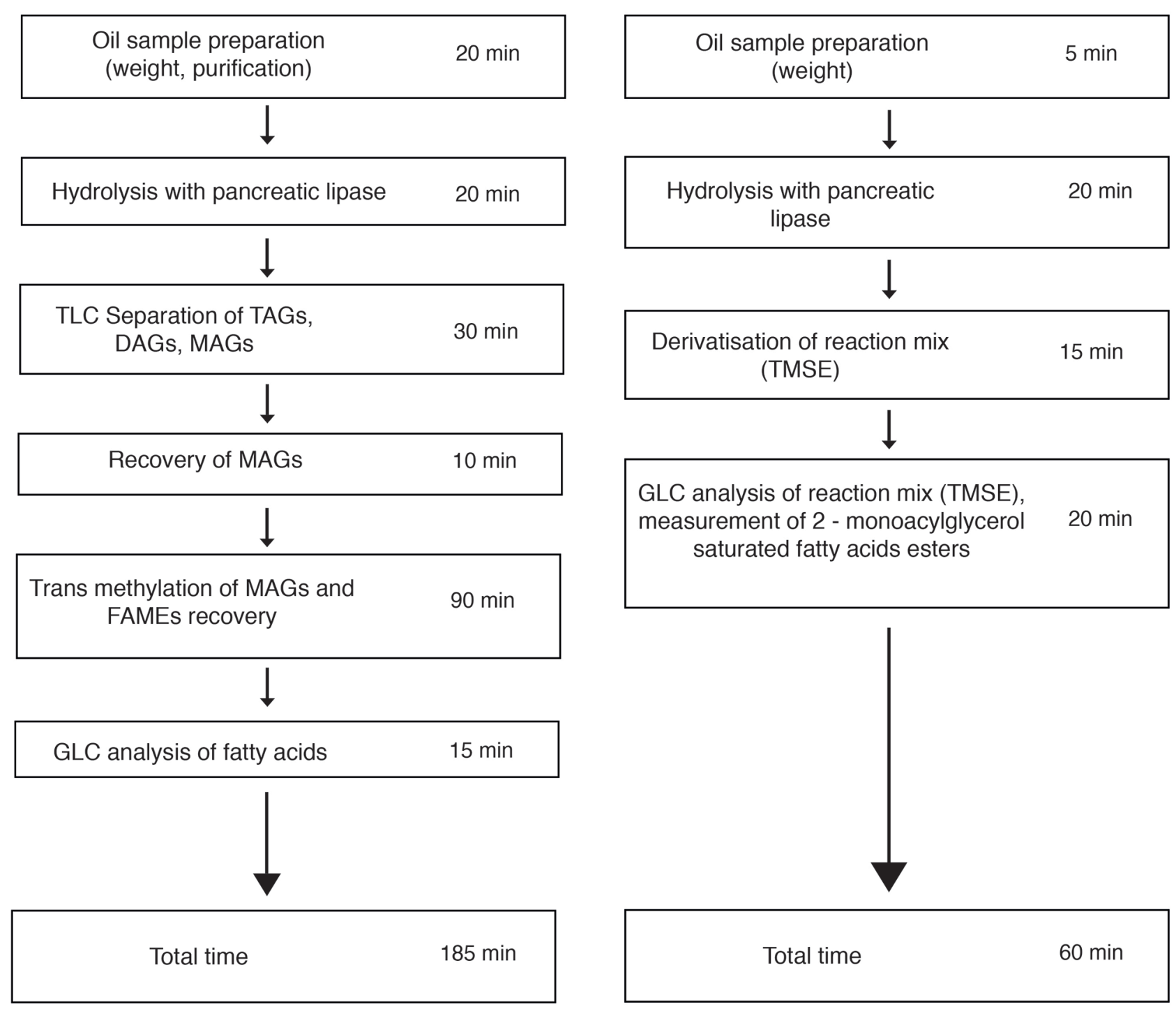

Fig. 7. Determination of the fatty acid composition at 2-position of TAG molecule by means of hydrolysis with pancreatic lipase, on the left the "traditional" method, on the right the improved one (nowadays adopted as official method by UE and IOC).

by capillary chromatography, after the only silylation was applied, and after some authors (Mariani, Conte, Lercker) demonstrated that some false positive results can depend on some compound already present in the preparative TLC used to separate MAGs from the reaction mixture, a new more performing method was developed that was less time consuming and also offers the possibility to check the reaction yield (Fig. 7).

Other researches spent attention to the whole fatty acids distribution, not only at 2-position, but at 1- and 3-, too, the important schools of Christie in Scotland and Damiani in Perugia (Italy) (Damiani et al., 1994) applied this not selective TAGs hydrolysis by means of the Grignard reaction, then the derivatised partial glycerides were separed by Silver nitrate HPLC.

In 1993, (Gallina Toschi et al., 1993) published an approach that determined the triacylglycerol composition of olive oil samples by stereospecific analysis after partial hydrolysis with ethyl magnesium bromide, derivatization, preparative chiral HPLC, transesterification, and GC quantitation of fatty acid methyl esters. The data obtained for position $s n-2$ were compared with those from capillary GC analysis of monoacyl sn-2glycerols after enzymatic lipolysis of triacylglycerols.

Vichi et al. (2007) applied the same approach and the positional distribution of fatty acids (FA) in triacylglycerols (TAG) of 47 virgin olive oils from diverse cultivars grown in distinct areas of North-Eastern Italy was studied. Few data were previously available on oils from these geographical areas. The effects of climatic and geographical conditions on the stereospecific distribution of TAG in olive oil were confirmed. Moreover, the results of the stereospecific analysis were used to evaluate the preferential esterification position of each FA on the basis of the degree of unsaturation and the chain length. The data of the stereospecific analysis of olive oil TAG can contribute to the determination of the selectivity of olive fruit acyltransferases for distinct FA.

The development of HPLC makes this technique the more used for TAGs analysis, however, only a RI detector can be uses to avoid the overestimation of unsaturated TAGS if an UV 


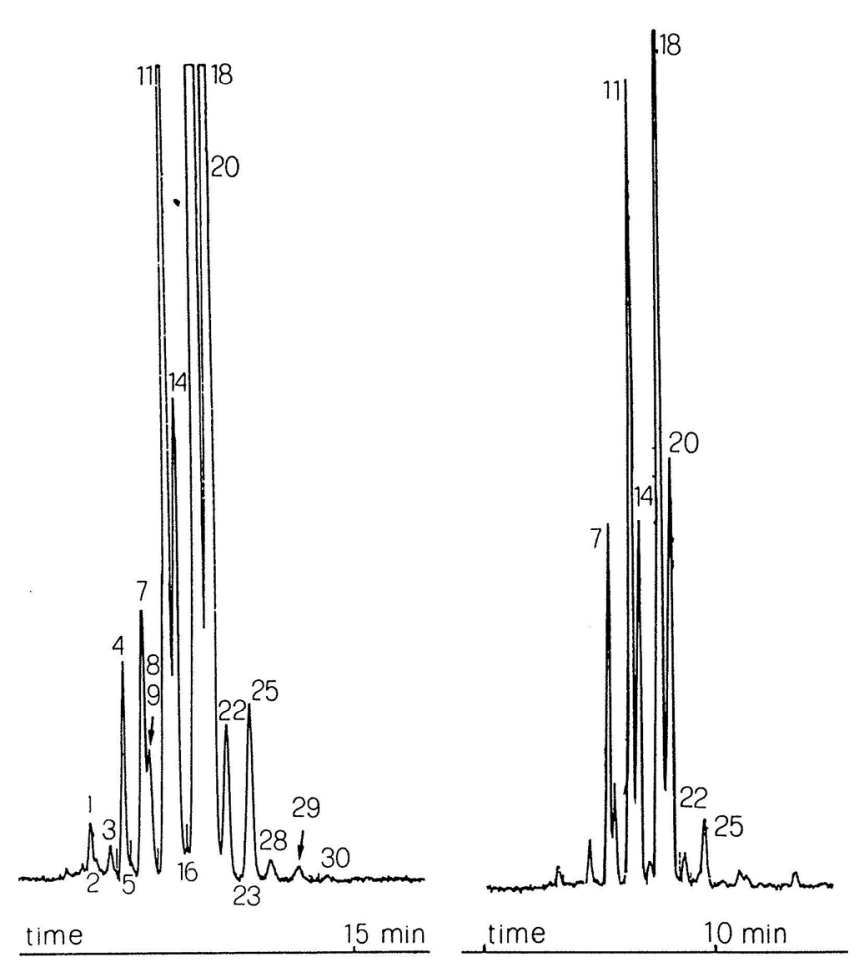

Fig. 8. HPLC analysis of TAGs by gradient elution with light scattering detection (Caboni et al., 1992 reproduced under permission).

detector is used, An alternative detector is the Light Scattering, Conte et al. used it in 1992 (Caboni et al., 1992) and fast analysis were possible, even if some doubts about the linearity were expressed (Fig. 8).

This kind of detector was recently improved ad leads to the production of the CAD (Lucci et al., 2018), used a new ultra high-pressure liquid chromatography method using charged aerosol detector (UHPLC-CAD) with an inverse-gradient solvent compensation has been developed for the analysis of triacylglycerols (TAGs) in extra-virgin olive oil. Using a gradient method with a superficially porous particles column, an improved separation of TAGs was obtained, with notably shortening of both solvent consumption and analysis time, in comparison with the IOC official method for ECN 42 analysis. Furthermore, an almost baseline separation of trilinolein was obtained. (Fig. 9) CAD provides good linearity $\left(\mathrm{R}^{2}>0.999\right)$ in the range of $0.05-10 \mu \mathrm{g}$ of trilinolein injected on column as well as uniformity of response factor for different TAG molecular species (Fig. 10). Finally, the proposed UHPLCCAD methodology has been successfully applied to the determination of trilinolein in low-linoleic acid extra-virgin olive oil mixed in different proportions with high-oleic sunflower oil, palm olein and a mix of them at different percentages of 2, 4, 6, 8 and $10 \%(\mathrm{w} / \mathrm{w})$. Good linearity was achieved in all the three blends with correlation coefficients greater than 0.975 in all cases.

The analysis of TAGs also is mandatory within the frame of official methods, as $\Delta$ ECN42, developed by Fedeli (2001), then adopted by IOC and lately by EEC, the scientific ground of this method is based on the different specificity of enzymes that are responsible for TAGs syntesys in fruits flesh and in seeds; an extension of this approach was the so called Global Method developed in Sevilla by Cert and Moreda (2000).

The group of Udine applied different analytical approaches to check the reliability of these two methods.

Two data elaboration approaches for evaluating olive oils authenticity were compared: (I) determination of the difference between the theoretical and actual amounts of triacylglycerols with partition number $42(\Delta \mathrm{ECN} 42 \leq|0.2|)$; and (II) the global method, which considers also partition numbers 44 and 46 (returning a "correct"/"not correct" result). Analysis of 31 genuine extra virgin olive oil samples was performed using different analytical methods, namely liquid chromatography (LC) coupled with a refractive index detector (RID) and LC coupled with a mass spectrometry (MS), and the results compared. (Fig. 11) Several false positives were highlighted using the $\triangle E C N 42$ limit with both instrumental approaches. The global method algorithm returned "correct" results for all the samples analysed (except two that gave no results) with LC-MS; on the other hand, 10 false positives were obtained elaborating data deriving from NARP-LC-RID analysis (Beccaria et al., 2015).

Within the OLEUM project, a simple GC analysis of TAGs had been applied too, and results suggested that it could be useful as a tool to assess the purity of selected oils.

A peculiar class of minor compounds are the volatile ones, it's well known that VOOs undergo to sensory evaluation, so since the beginning of this approach, chemists were interested in evaluating the volatile compounds that can be responsible for selected sensorial effects.

At Udine University, we earlier developed and approach by analyising with a peculiar GC-MS devise, developed by Barcarolo et al. (1992) the volatile fraction of oils that the IOC disseminated as standards to carry out sensory assessors training (Fig. 12).

The chemiometric evaluation of results suggested that some relationship could exist between some compounds and selected defects (Procida et al., 2005) (Fig. 13).

The invention of SPME greatly improved the possibility of analysis of a huge number of samples in a reduced time: in 1973, at Bologna University, the apparatus was rather space, time and skillness consuming, (Fig. 14) the comparison with SPE surely explain the advantages of the latter technique.

SPME analysis of volatile compounds of olive oils was optimized by Vichi et al. in 2003 evaluating any parameter that can affect the performances of the analysis: time of fiber exposition, temperature, fiber coating etc. (Vichi et al., 2003) (Fig. 15).

Then, several applications were developed concerning $e . g$. oxidative status, geographical origin.

The development of "positive" volatile compounds in olive mainly happens during the malaxion, where a number of enzymatic reactions takes place.

Maijetic added (Majetić et al., 2013) increasing amount of polar extract from Bianchera (a cultivar very rich in polyphenols) to Busa olive kidney during malaxion and monitored the development of volatile that was affected by the action of polyphenols on the enzymatic pool.

The method developed in cooperation with Vichi was then applied to develop a research to investigate the possibility of get an interpretation of sensory evaluation in the light of an instrumental chemical analysis: a number of sample that 


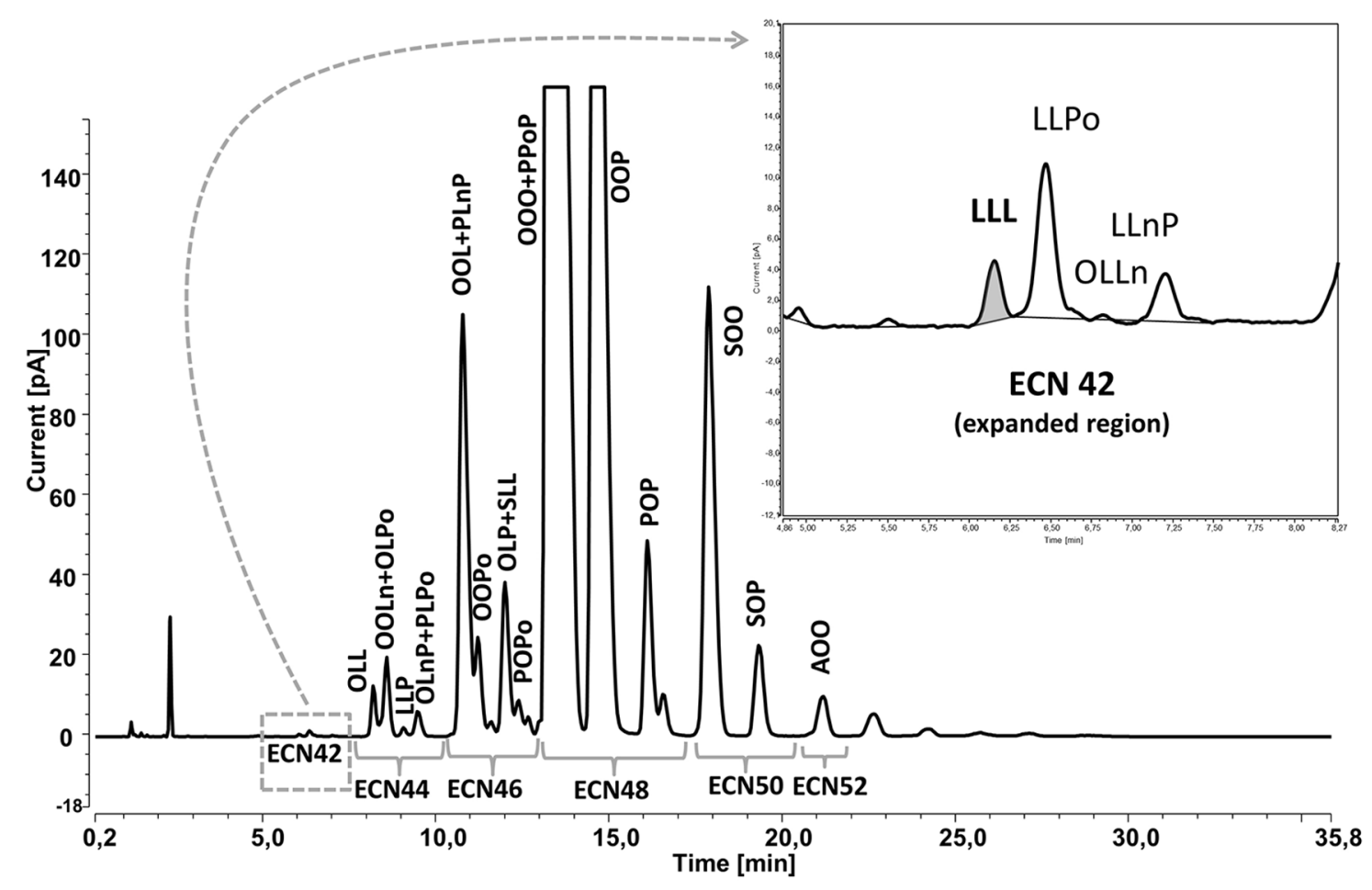

Fig. 9. UHPLC analysis of TAGs by gradient elution and charged aerosol detector (Lucci et al., 2018 reproduced under permission).

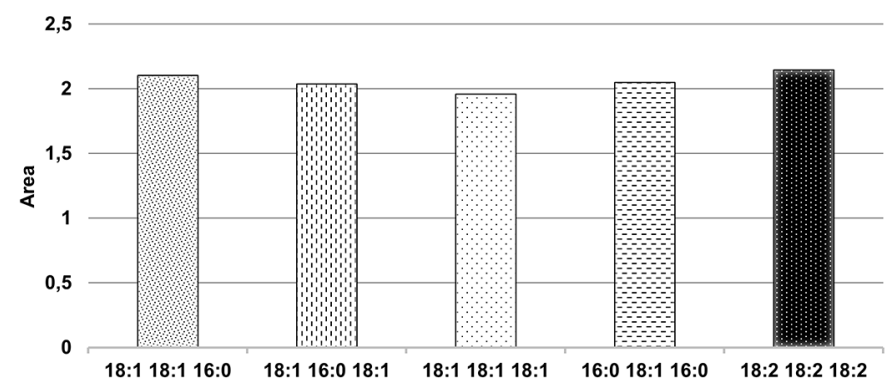

Fig. 10. UHPLC analysis of TAGs by gradient elution and charged aerosol detector: Uniformity of response factor for different TAGs (Lucci et al., 2018 reproduced under permission).

already underwent to sensory evaluation was analysed by HSSPME-GC-MS.

The chemoimetric evaluation that was applied needs for a number of signals, so that not the area of a peak was considered itself, but the pool of single MS fragments.

The analysis was applied to several samples of defected oils and markers of defects were identified, a mathematical expression was developed that takes care of the presence of substances belonging to the "green" sensory attributes, able to mask the presence of defects; results for defects of "moldearth, humid", "frostbitten olives" and "winegary".

Are summarised in Tables 2-4, some algorithm are also reported.

The official method form sensory evaluation of virgin olive oils, named "panel test", uses the median value of selected characteristics detected by a group of sensory assessors, we
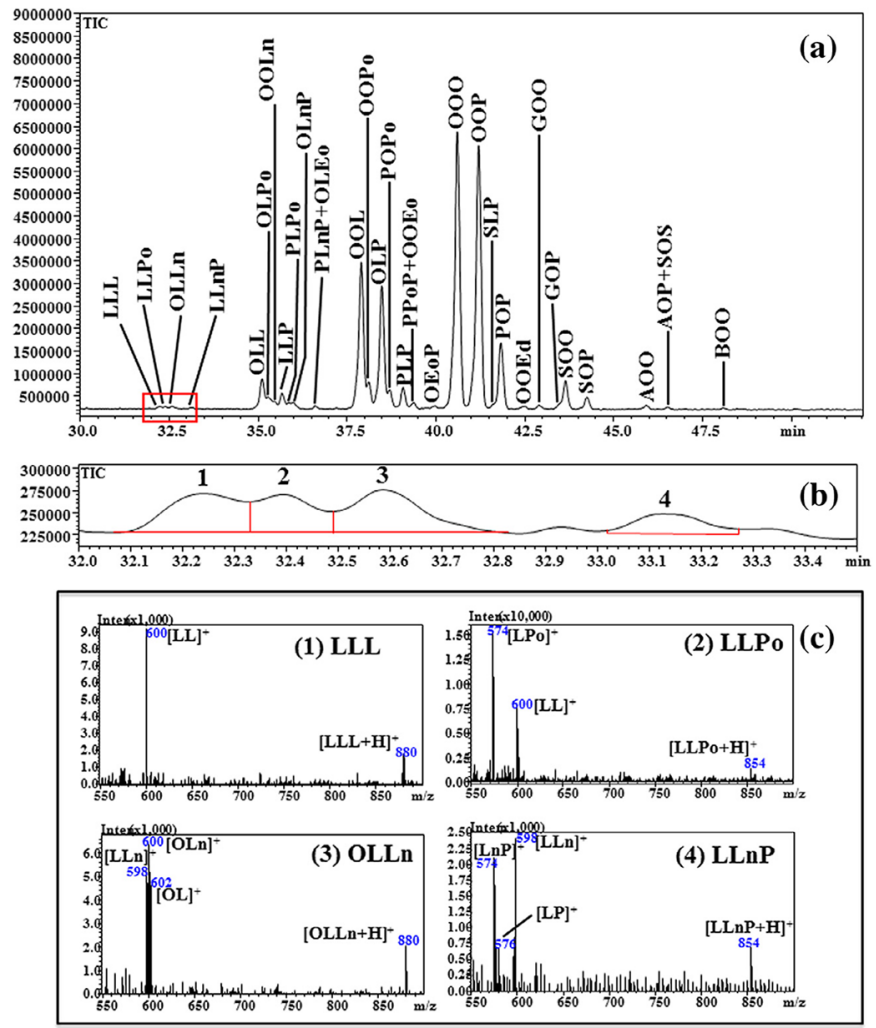

Fig. 11. UHPLC analysis of TAGs by using a RID and a MS detectors (Beccaria et al., 2015 reproduced under permission). 

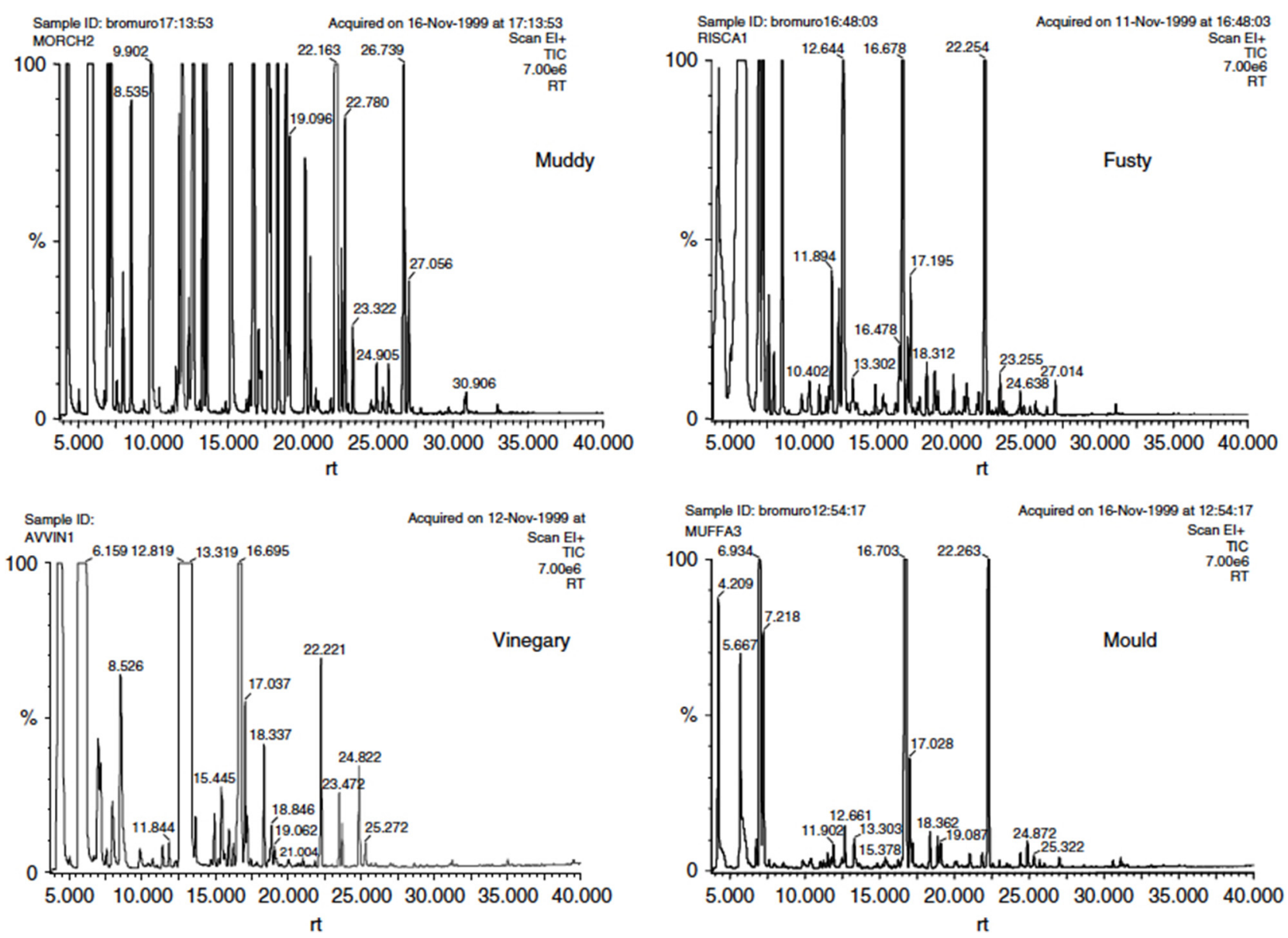

Fig. 12. TIC traces of volatile compounds of defected virgin olive oils (Procida et al., 2005, reproduced under permission).

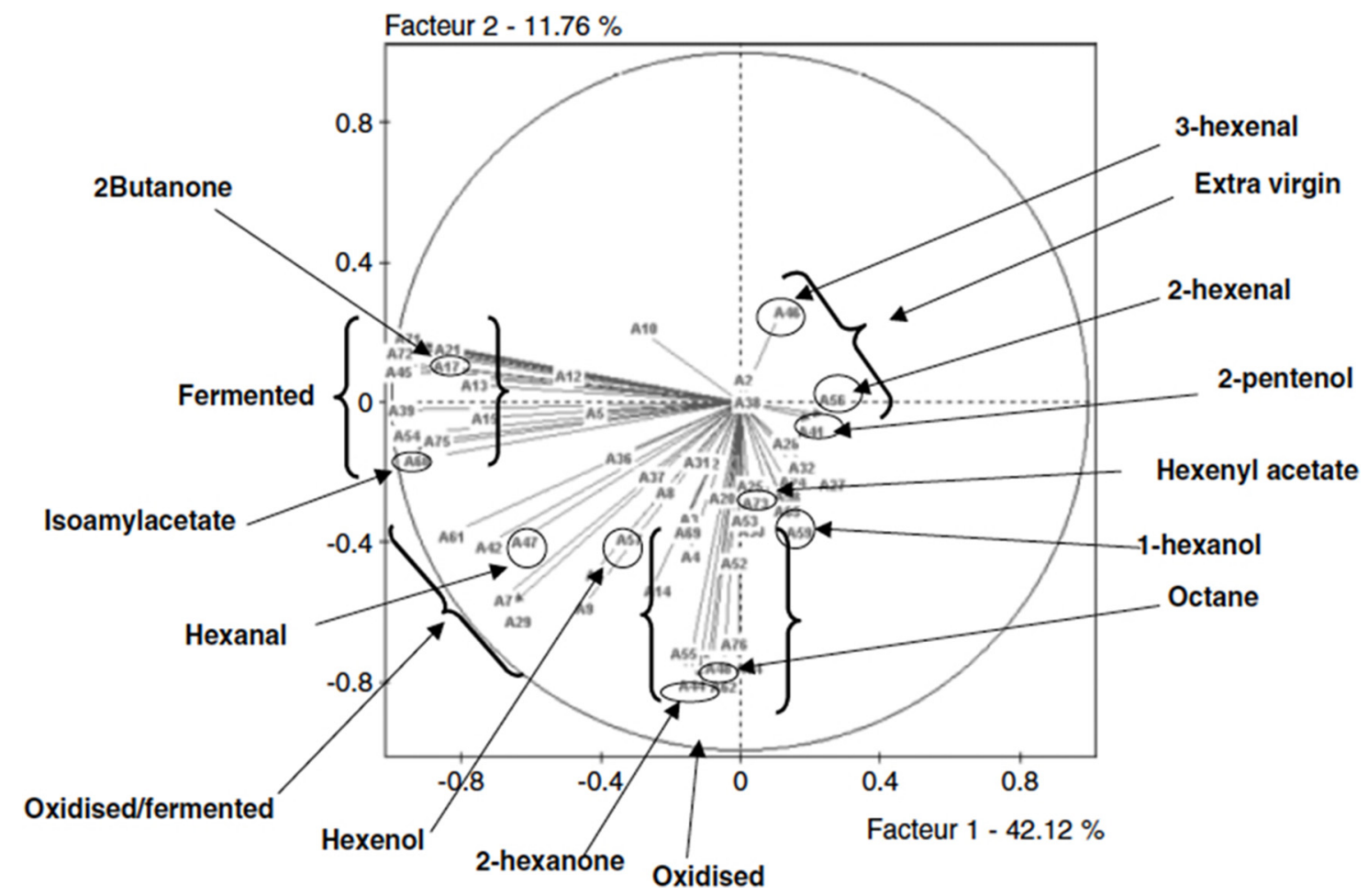

Fig. 13. Chemometric evaluation fitting the presence of selected volatile compounds to the presence of selected sensory evaluations (Procida et al., 2005, reproduced under permission). 


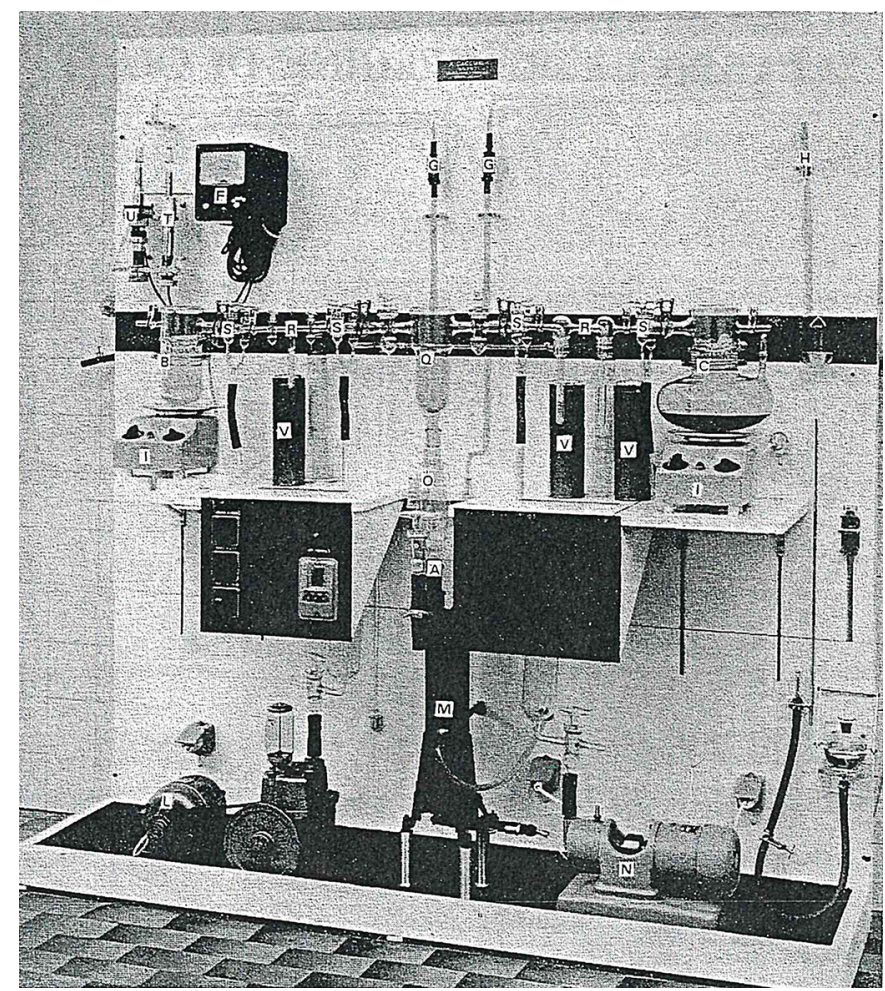

Fig. 14. Apparatus for the extraction and recovery of volatile compounds from olive oils used at University of Bologna, years 1971-1974.
Table 2. Head Space-SPME-GC-MS analysis of a defected oil already evaluated by a sensory panel: defect "mold-earth-humid", list of compounds evaluated as significant by Chemometric analysis, compounds with an asterisk are those recognized as the "green" sensation group. Two algorithm are reported where the green compounds effect had been separated by those belonging to the defect and an "instrumental" median had been calculated (Moret and Conte, 2014 unpublished data).

\begin{tabular}{|c|c|c|c|c|c|}
\hline \multicolumn{6}{|c|}{ Mold-Earth-Humid } \\
\hline \multicolumn{2}{|r|}{ DB-WAX } & \multicolumn{4}{|c|}{$\mathrm{DB}-5 \mathrm{~ms}$} \\
\hline 1 & n-hexane & 1 & Ethanol & 14 & $\begin{array}{l}\text { 2-methyl butanoic } \\
\text { acid ethyl ester }\end{array}$ \\
\hline 2 & n-Heptane & 2 & Acetone & 15 & (E)-2-hexenal $(*)$ \\
\hline 3 & Octane & 3 & Methyl acetate & 16 & (Z)-3-hexen-1-ol (*) \\
\hline 4 & Acetone & 4 & n-hexane & 17 & (E) 2-hexen-1-ol (*) \\
\hline 5 & Methyl acetate & 5 & Acetic acid & 18 & 1-hexenol $(*)$ \\
\hline 6 & Ethyl acetate & 6 & Ethyl acetate & 19 & Heptanal \\
\hline 7 & Ethanol & 7 & $\begin{array}{l}\text { 2-methyl-1- } \\
\text { butanol }\end{array}$ & 20 & $\begin{array}{l}\text { 3-ethyl-1.5- } \\
\text { octadiene }(*)\end{array}$ \\
\hline 8 & Hexanal(*) & 8 & $\begin{array}{l}\text { (E)-2-methyl-2- } \\
\text { butenal }\end{array}$ & 21 & 2-octanone \\
\hline 9 & 1-butanol & 9 & 1-penten-3-ol $(*)$ & 22 & $\begin{array}{l}\text { (Z)-3-hexen- } \\
\text { 1-ol-acetate }\end{array}$ \\
\hline 10 & 1-penten-3-ol $(*)$ & 10 & 1-penten-3-one ${ }^{*}$ & & \\
\hline 11 & 3-methyl-1-butanol & 11 & 3-pentanone & & \\
\hline 12 & (E)-2-hexenal $(*)$ & 12 & Hexanal $(*)$ & & \\
\hline \multirow[t]{4}{*}{13} & $\begin{array}{l}\text { (Z)-3-hexen- } \\
\text { 1-ol-acetate }(*)\end{array}$ & 13 & Octane & & \\
\hline & & Pola & Ir column $\left(\mathrm{R}^{2} 0.93\right.$ & & \\
\hline & $\sum_{\text {markers }}-\sum_{\mathrm{N}}$ & & $\begin{array}{l}\text { compounds }=-2.526 \\
\text { olar column }\left(\mathrm{R}^{2} 0 .\right.\end{array}$ & & +11.677 \\
\hline & $\sum_{\text {markers }} / \sum$ & & compounds $=-0.7476$ & & +3.8967 \\
\hline
\end{tabular}

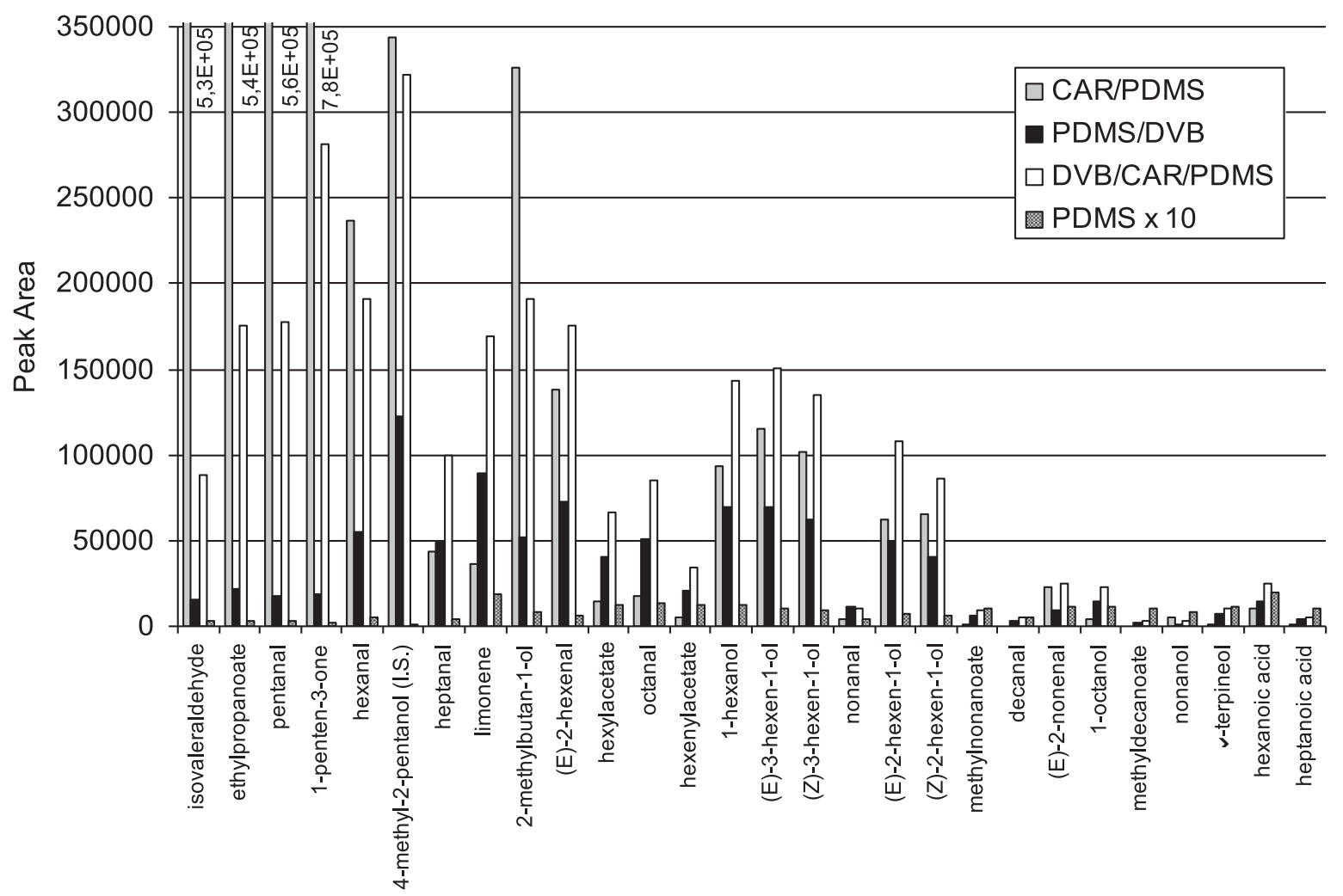

Fig. 15. Evaluation of performances of different SPME coating in analysis of extra virgin olive oil volatile compounds (Vichi et al., 2003, reproduced under permission). 
Table 3. Head Space-SPME-GC-MS analysis of a defected oil already evaluated by a sensory panel: defect "frosbitten olives", list of compounds evaluated as significant by Chemometric analysis, compounds with an asterisk are those recognized as the "green" sensation group. Two algorithm are reported where the green compounds effect had been separated by those belonging to the defect and an "instrumental" median had been calculated (Moret and Conte, 2014 unpublished data).

\begin{tabular}{|c|c|c|c|}
\hline \multicolumn{4}{|c|}{ Frosbitten olives } \\
\hline \multicolumn{2}{|c|}{ DB-WAX } & \multicolumn{2}{|c|}{$\mathrm{DB}-5 \mathrm{~ms}$} \\
\hline 1 & n-hexane & 1 & Ethanol \\
\hline 3 & Acetone & 3 & 2-methyl-2-propenal \\
\hline 4 & Methyl acetate & 4 & n-Hexane \\
\hline 5 & Ethyl acetate & 5 & Acetic acid \\
\hline 8 & (E)2-hexenal $(*)$ & 8 & 2-methyl-butanal \\
\hline 9 & (Z)3-hexen-1-ol-acetate $\left(^{*}\right)$ & 9 & 1-penten-3-ol (*) \\
\hline 10 & 1-hexanol $(*)$ & 10 & 1-penten-3-one $(*)$ \\
\hline 11 & (E)3-hexen-1-ol $(*)$ & 11 & 3-pentanone \\
\hline 12 & (Z)3-hexen-1-ol (*) & 12 & Hexanal $(*)$ \\
\hline 13 & (E)2-hexen-1-ol (*) & 13 & Octane \\
\hline \multirow{4}{*}{14} & & 18 & 2 octanone \\
\hline & & 19 & (Z)3-hexen-1-ol acetate $(*)$ \\
\hline & \multicolumn{3}{|c|}{$\begin{array}{c}\text { Polar column }\left(\mathrm{R}^{2} 0.7999\right) \\
\sum_{\text {markers }}-\sum_{\text {green compounds }}=5.8823 \times \mathrm{M}_{\mathrm{d}}-7.9001 \\
\text { Non polar column }\left(\mathrm{R}^{2} 0.7137\right)\end{array}$} \\
\hline & \multicolumn{3}{|c|}{$\sum_{\text {markers }} / \sum_{\text {green compounds }}=1.3059 \times \mathrm{M}_{\mathrm{d}}-1.2257$} \\
\hline
\end{tabular}

Table 4. Head Space-SPME-GC-MS analysis of a defected oil already evaluated by a sensory panel: defect "winegary" list of compounds evaluated as significant by Chemometric analysis, compounds with an asterisk are those recognized as the "green" sensation group. Two algorithm are reported where the green compounds effect had been separated by those belonging to the defect and an "instrumental" median had been calculated (Moret and Conte, 2014 unpublished data).

\begin{tabular}{|c|c|c|c|}
\hline \multicolumn{4}{|c|}{ Winegary } \\
\hline \multicolumn{2}{|c|}{ DB-WAX } & \multicolumn{2}{|c|}{$\mathrm{DB}-5 \mathrm{~ms}$} \\
\hline 1 & n-hexane & 1 & Ethanol \\
\hline 2 & Heptane & 2 & Acetone \\
\hline 3 & Acetone & 3 & Methyl acetate \\
\hline 4 & Methyl acetate & 4 & n-hexane \\
\hline 5 & Ethyl acetate & 5 & Acetic acid \\
\hline 6 & Ethanol & 6 & Ethyl acetate \\
\hline 7 & 1-pentanone & 7 & 2-methyl-1-.propanol \\
\hline 8 & (1-penten-3-one $(*)$ & 8 & 2-methyl butanal \\
\hline 9 & Hexanal $(*)$ & 9 & 1-penten-3-ol $(*)$ \\
\hline 10 & 1-penten-3-ol (*) & 10 & 1-penten-3-one $(*)$ \\
\hline 11 & (E) hexenal $(*)$ & 11 & 3-pentanone \\
\hline 12 & (Z) 3-hexen-1-ol acetate $(*)$ & 12 & Hexanal (*) \\
\hline 13 & (E) 3-hexen-1-ol $(*)$ & 13 & Octane \\
\hline 14 & (z) 3-hexen-1-ol (*) & 14 & 2-butanoic acid ethyl ester \\
\hline \multirow[t]{8}{*}{15} & Acetic acid & & \\
\hline & & 15 & (E) 2-hexenal (*) \\
\hline & & 16 & (Z) 3-hexen-1-ol \\
\hline & & 17 & (E) 2-hexen-1-ol \\
\hline & & 18 & 1-hexenol \\
\hline & & 19 & 3-ethyl-1.5-octadiene $(*)$ \\
\hline & & 20 & 2-octanone \\
\hline & \multicolumn{3}{|c|}{$\begin{array}{l}\sum_{\text {markers }}=11.209 \times \mathrm{M}_{\mathrm{d}}-14.63\left(\mathrm{R}^{2} 0.7137\right) \\
\text { rs } / \sum_{\text {green compounds }}=0.3552 \times \mathrm{M}_{\mathrm{d}}-0.3711\left(\mathrm{R}^{2} 0.8743\right)\end{array}$} \\
\hline
\end{tabular}


Table 5. A comparison between values of the Median of the defect of "winegary" and those calculated on the basis of GC-MS analysis: different levels of agreement for different applied algorithm.

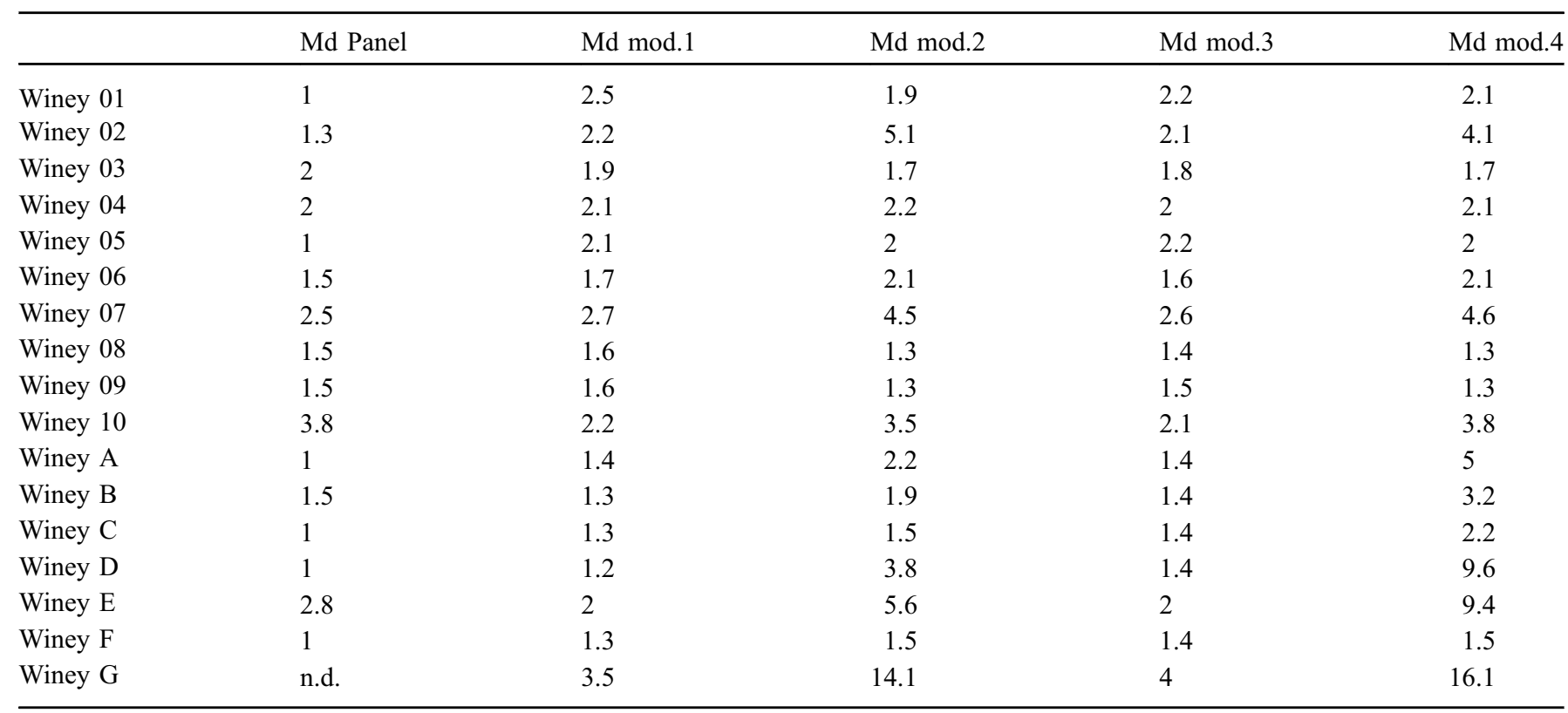
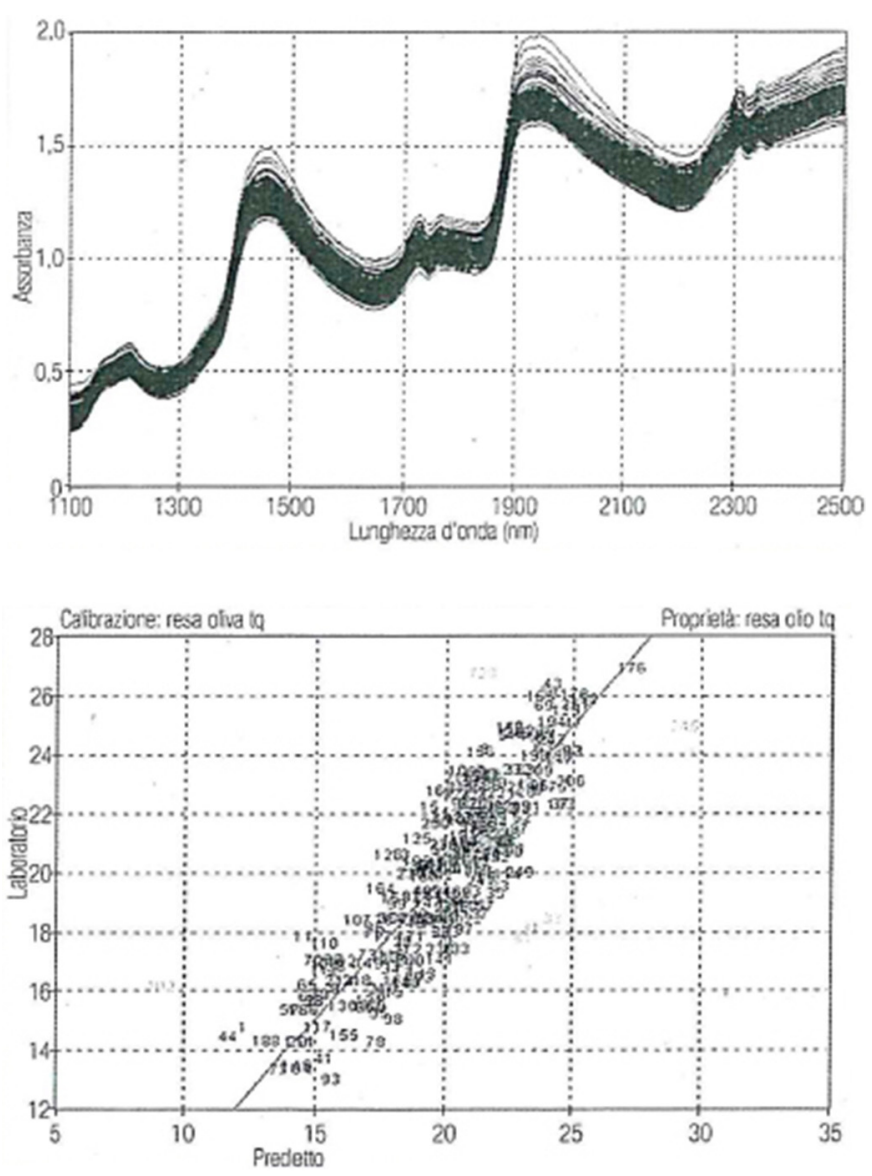

Fig. 16. NIR Analysis of olive paste and prediction of the content of oil (Conte et al., 2003). calculated an "instrumental median" and compared the results with those obtained by the panels, results are reported in Table 5: it is easy to note that in the case of the winegary defect, generally a good agreement exists between panel median and instrumental median.

The possibility to apply different analytical approach for fast analysis was evaluated by an experimental work on NIR.

A transmittance NIR was used, with two application; in the olive oil mill to predict the content of oil in the fruit and on the extracted oil to measure main analytical parameters.

Results of both tasks are reported in Figures 16 and 17 (Conte et al., 2003).

Last but not least, the problem of contaminants: we studied the presence of PAHs through the production chain of all categories of oils extracted from olives (including pomace), several contamination sources were identified and a rapid, simple and performing analytical method was developed for their determination, the method met the EEC required characteristic for PAHs evaluation method in fats and oils. Figure 18 reproduces the HPLC traces obtained after SPE sample preparation. (Purcaro et al., 2008).

PAHs are components of "mineral oils", too, their presence was highlighted by Grob et al. while PAHs were determined in several samples of foods, the deep knowledge of these compounds show that two main categories of compound are present: Mineral oil saturated hydrocarbons (MOSH) and Mineral oil Aromatic Hydrocarbons (MOAH), were detected in different concentration in olive oils (blend refined with virgin) and in Olive pomace oil but they are practically absent in extra virgin olive oils.

Their analytical determination is still a challenge, mainly for what concerns LOD and LOQ, the only validated method uses an LC-GC apparatus with a reproducibility relative standard deviation of $10 \%$. 

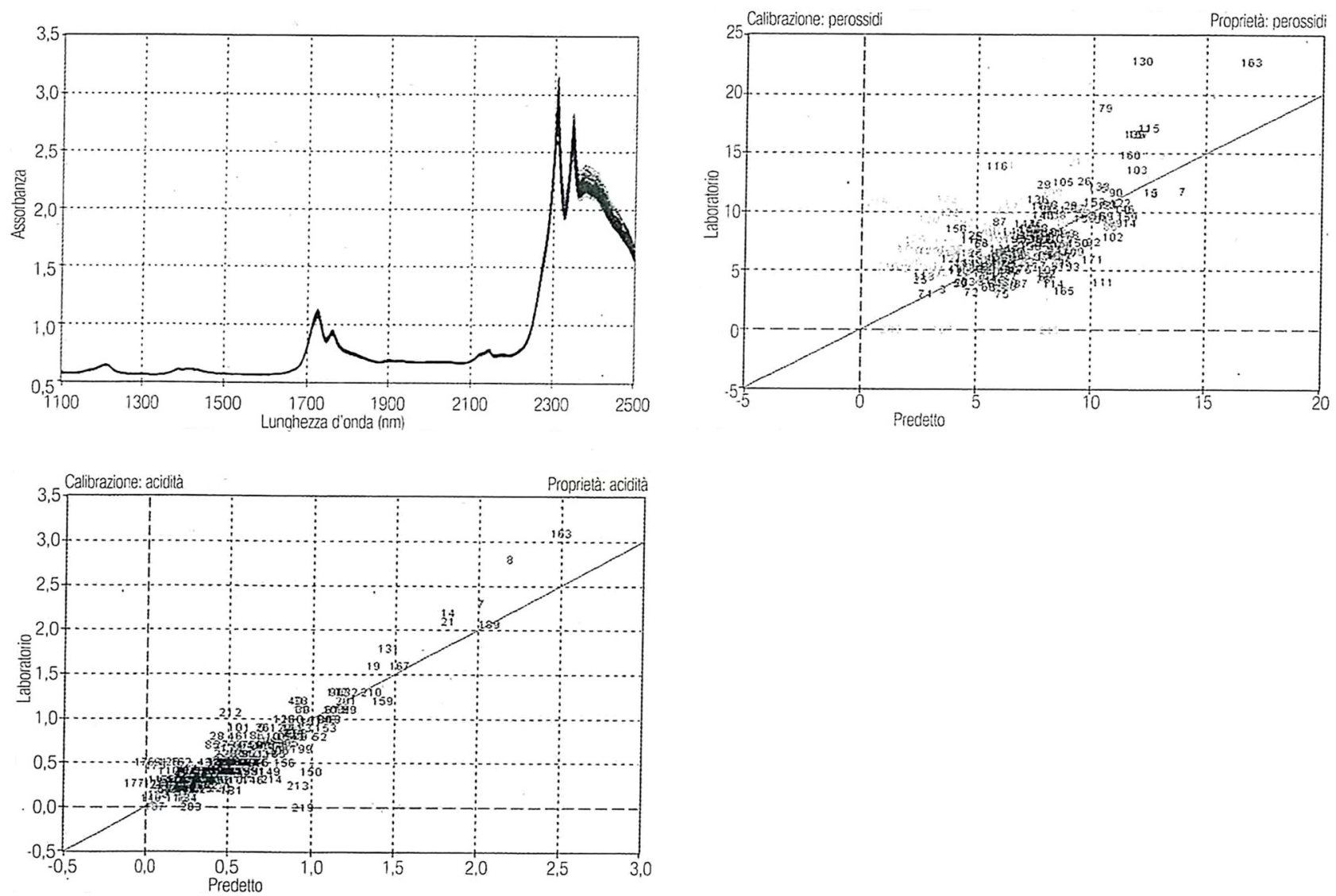

Fig. 17. NIR Analysis of extra virgin olive oil; on the left, 255 spectra of oil, right calibration curve for PV evaluation, left, bottom: calibration curve of free acidity (Conte et al., 2003, reproduced under permission).

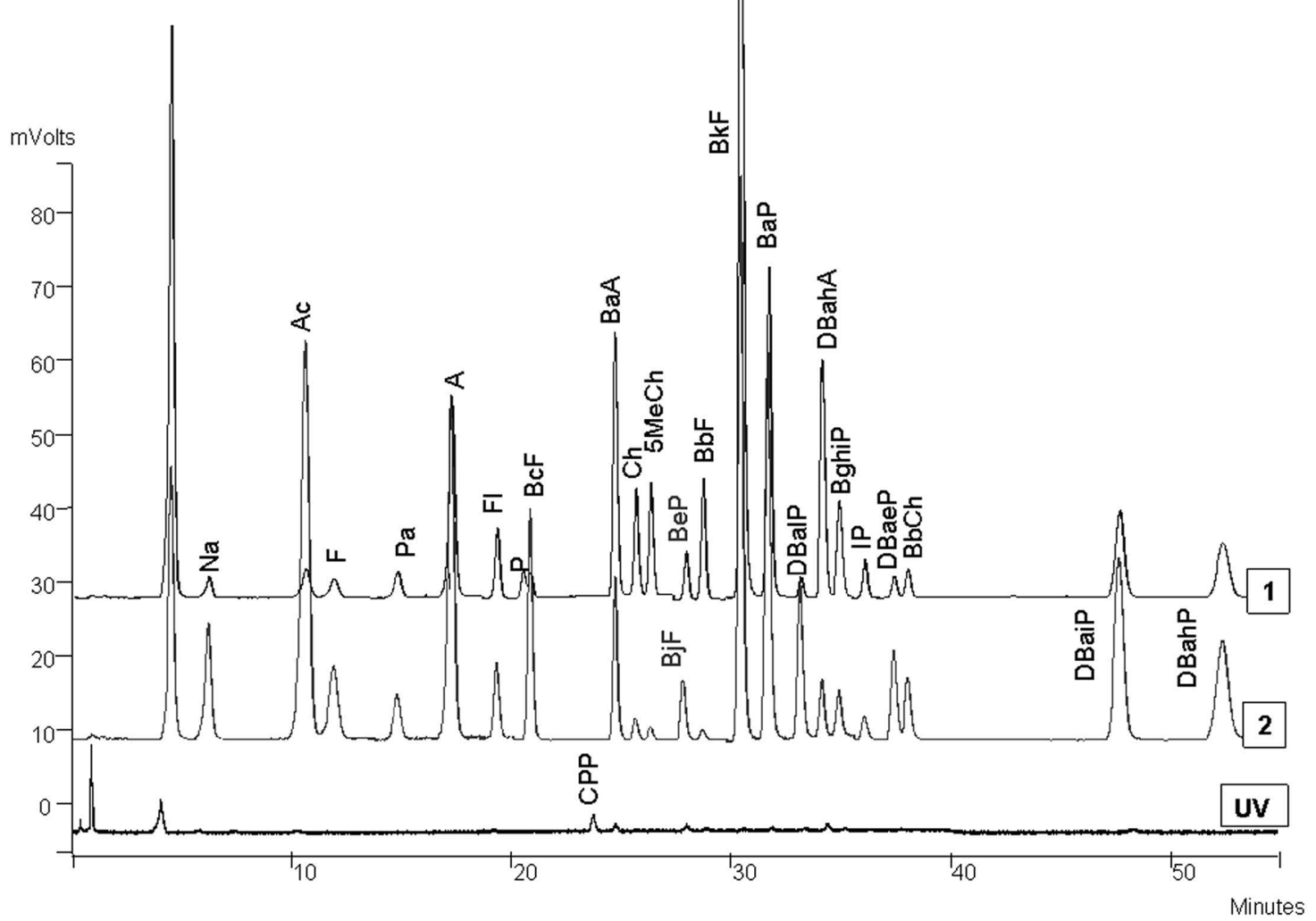

Fig. 18. HPLC analysis of PAHs extracted by SPE (Silica, $5 \mathrm{~g}$ ), and determined both ny spectrofluorescence and UV detection (Purcaro et al., 2008, reproduced under permission). 
A debat was about the origin of MOSH and MOAH, the presence of hopanes was checked as a witness of their petrogenic origin. (Populin et al., 2004).

\section{Conclusions}

Despite the fact that olive oils are probably one of the most deeply studied food, a number of new knowledge arise day by day, thanks to the improvement of analytical instrumentation.

Recent decades (1960-nowadays) mainly applied separative analytical methods and the evaluation of purity and quality was developed by target approaches, while more recently, untargeted approaches seem very promising, however the two approaches must be finely tuned in order to lead to results that can be compared avoiding to improve the level of litigation.

Surely the knowledge of the food matrix (olive oils in cases here discussed) remains a milestone for s serious approach to quality and purity control and can and must drive the evaluation of results and this is an human activity that never can be substituted by a blind confidence in results produced by a computerized instrument, in other word food chemists are absolutely necessary to drive any instrumental evolution.

\section{References}

Amelio M, Amelotti G, Cozzoli O, et al. 1993. Determinazione degli acidi grassi trans insaturi negli oli non idrogenati mediante gascromatografia su colonna capillare. risultati di una sperimentazione interlaboratorio (Attività della Commissione TecnicaSottocommissione «Oli Vegetali »). Riv Ital Sostanze Grasse 70: 561-566.

Barcarolo R, Casson P, Tutta C. 1992. Analysis of the volatile constituents of food by headspace GC-MS with reversal of the carrier gas flow during sampling. J High Resolut Chromatogr 15: 307-311.

Beccaria M, Moret E, Purcaro G, et al. 2015. Reliability of the $\triangle$ ECN42 limit and global method for extra virgin olive oil purity assessment using different analytical approaches. Food Chem 190: 216-225.

Bortolomeazzi R, De Zan M, Pizzale L, Conte L. 2000. Identification of new steroidal hydrocarbons in refined oils and the role of hydroxysterols as possible precursors. J Agric Food Chem 48: 1101-1105.

Caboni MF, Conte L, Lercker G. 1992. Rapid HPLC analysis of triacylglycerols by isocratic elution and light scattering detection. Ital J Food Sci 2: 125-132.

Capella P, Lercker G, Conte L. 1975. Determinazione degli acidi grassi saturi mediante GLC previa separazione su strato sottile. STA\&NU 4: 235-238.

Cert A, Moreda W. 2000. Algorithms for the detection of hazelnut in olive oil. Grasas Y aceites 51: 143-145.

Cert A, Lanzon A, Carelli AA, Albi T, Amelotti G. 1994. Formation of stigmasta-3.5-diene in vegetable oils. Food Chem 49: 287-29.

Conte L, Lercker G, Capella P, Catena M. 1979. Composizione dell'olio di semi di lino. Riv Ital Sostanze Grasse 56: 339-342.
Conte L, Leoni O, Palmieri S, Capella P, Lercker G. 1989. Half seed analysis: rapid chromatographic determination of the main fatty acids of sunflower seed. Plant Breed 102: $158-165$.

Conte L, Brussolo G, Pizzale L, Carazzolo A, Meurens M, Pavan O. 2003. Applicazione della tecnica NIR alla valutazione della qualità nel settore della produzione di olio di oliva. Riv Ital Sostanze Grasse 80: 223-227.

Damiani P, Santinelli F, Simonetti MS, Castellini M, Rosi M. 1994. Comparison between 2 procedures for stereospecific analysis of triacylglycerols from vegetable oils I: Olive oil. $\mathrm{J} \mathrm{Am} \mathrm{Oil} \mathrm{Chem}$ Soc 71: 1157-1162.

Fedeli E. 2001 Analysis of triglycerides in the determination of the genuineness of olive oils. Riv Ital Sostanze Grasse 76: 245-247.

Gallina Toschi T, Christie WW, Conte L. 1993. Capillary gas chromatography combined with high performance liquid chromatography for the structural analysis of olive oil triacylglycerols. $J$ Sep Sci 16: 725-730.

Geeraert E, Sandra P. 1985. Capillary gc of triglycerides in fats and oils using a high-temperature phenylmethylsilicone stationary phase. J High Resolut Chromatog Chromatog Comm 8: 415-422.

Itoh T, Tamura T, Matsumoto T. 1973. Sterol composition of 19 vegetable oils. J Am Oil Chem Soc 50: 122-125.

Lercker G, Frega N, Capella P, Conte L. 1981. La gascromatografia su colonne capillari (HRGC) nello studio dell'insaponificabile degli oli vegetali. Riv Ital Sostanze Grasse 58: 324-330.

Lucci P, Moret S, Buchini F, Ferlat G, Conte L. 2018. Improved analysis of olive oils triacylglycerols by UHPLC-charged aerosol detection. J Food Comp Anal 66: 230-236.

Majetić Germek V, Koprivnjak O, Butinar B, Pizzale L, BučarMiklavčič M, Conte L. 2013. Influence of Phenols Mass Fraction in Olive (Olea europaea L.) Paste on Volatile Compounds in Buža Cultivar Virgin Olive Oil. J Agric Food Chem 61: 5921-5927.

Montefredine A, Laporta L. 1959. Applicazione della spettrometria all'analisi dell'olio d'oliva. Oliiminerali y grassi et saponi 36: 31-36.

Morchio G, Di Bello A, Mariani M, Fedeli E. 1989. Individuzione di particolari oli rettificati in oli vergini di olive. Riv Ital Sostanze Grasse 66: 251-257.

Motta L, Brianza M, Stanga F, Amelotti G. 1983. Analisi gascromatografica di gliceridi parziali dopo lipolisi con lipasi pancreatica. Riv Ital Sostanze Grasse 60: 625-633.

Niewiadomski H. 1975. The sterol hydrocarbons in edible oils. Die Nahrung 19: 525-536.

Populin T, Biedermann M, Grob K, Moret S, Conte L. 2004. Relative hopane content confirming the mineral origin of hydrocarbons contaminating foods and human milk. Food Addit Contam 21: 893-904.

Procida G, Giomo A, Cichelli A, Conte L. 2005. Study of volatile compounds of defective virgin olive oils and sensory evaluation: a chemometric approach. J Sci Food Agric 85: 2175-2183.

Purcaro G, Moret S, Conte L. 2008. Rapid SPE-HPLC determination of the 16 European priority polycyclic aromatic hydrocarbons in olive oils. J Sep Sci 31: 3936-3944.

Vichi S, Castellote AI, Pizzale L, Conte L, Buxaderas S, LopezTamames E. 2003 Analysis of virgin olive oil volatile compounds 
by head space solid phase microextraction coupled to gas chromatography with mass spectrometric and flame ionization detection. J Chromatog A 983: 19-33.
Vichi S, Pizzale L, Conte L. 2007. Stereospecific distribution of fatty acids in triacylglycerols of olive oils. Eur J Lipid Sci Technol 109: $72-78$.

Cite this article as: Conte L. 2020. The Chemistry of Olive Oil: an endless story. OCL 27: 28. 